\title{
Studying the generation of alternatives in public policy making processes
}

\author{
Valentina Ferretti ${ }^{\mathrm{a}, \mathrm{b}}$, Irene Pluchinotta ${ }^{\mathrm{c}, *}$, Alexis Tsoukiàs $^{\mathrm{c}}$ \\ ${ }^{a}$ Department of Architecture, Built Environment and Construction Engineering (ABC), Politecnico di Milano, Italy \\ ${ }^{\mathrm{b}}$ Department of Management, London School of Economics and Political Science, London, United Kingdom \\ ${ }^{c}$ LAMSADE-CNRS, PSL Research University, Université Paris Dauphine, Place du Maréchal de Lattre de Tassigny, 75016 Paris, France
}

\section{A R T I C L E I N F O}

\section{Article history:}

Received 14 August 2017

Accepted 31 July 2018

Available online 8 August 2018

\section{Keywords:}

(D) Decision processes

Policy analytics

Decision analysis

Policy design

\begin{abstract}
A B S T R A C T
The design of alternatives is an essential part of decision making that has been less studied in theory and practice compared to alternatives' evaluation. This topic is particularly relevant in the context of public policy making, where policy design represents a crucial step of the policy cycle since it determines the quality of the alternative policies being considered. This paper attempts to formalise the decision aiding process in two real interventions dealing with alternatives' generation for territorial policy making in Italy. The aim of this research is to understand what generates novelty within the alternatives' design phase of a decision aiding process, i.e. what allows to expand the solution space and discover new alternatives to solve the problem under consideration. It demonstrates ways in which novelty in decision processes can be supported by Operational Research/Multicriteria Decision Aiding tools. The two case studies are used to answer the following questions: (i) Why have new alternatives arose during the policy making process? (ii) How have they been generated? (iii) Which consequences did they lead to? and (iv) What generated novelty in the process? The results highlight two main reasons that can expand the solution space within a decision aiding process: (i) dissatisfaction (of the client, of the analyst or of the relevant stakeholders, especially when dealing with public policies) with respect to the solutions currently proposed to the decision making problem and (ii) opportunity for a change in one of the variables/constraints.
\end{abstract}

(c) 2018 Elsevier B.V. All rights reserved.

\section{Introduction}

In a time when policy makers are tasked with developing innovative solutions for increasingly complex policy problems, the need for intelligent design of policy alternatives has never been greater (Howlett, Mukherjee, \& Woo, 2015b). Policy makers must avoid simply advocating "stock" solutions unless this is called for by the limited nature of the available time for new designs (May, 1981). The design of alternatives to a decision problem is thus an essential part of the decision aiding process. However, it has been less studied in theory and practice compared to alternatives' evaluation (e.g. Alexander, 1982), and this is particularly relevant in the context of public policy making. From the standpoint of decision analysts, potentially involved in supporting policy making processes, this also represents a challenge.

\footnotetext{
* Corresponding author.

E-mail addresses: V.Ferretti@lse.ac.uk, valentina1.ferretti@polimi.it (V. Ferretti), irene.pluchinotta@dauphine.fr (I. Pluchinotta), alexis.tsoukias@dauphine.fr (A. Tsoukiàs).
}

Public policy alternatives are "options for government action comprised of different sets of policy means-that is policy tools and their calibrations-bundled together into packages of measures which are expected by their designers to be capable of attaining specific kinds of policy outcomes" (Howlett \& Rayner, 2013, p.171).

From the point of view of both research and practice (Anderson, 1975; Dunn, 1981; Dye, 1972; Jenkins, 1978), policy making is a long term public decision making process facing five major complexities: (i) the use of public resources and commons; (ii) the involvement of multiple stakeholders in a "de facto" participative process; (iii) the long time horizon; (iv) the requirements of legitimation and accountability; ( $v$ ) the need for the deliberation act of deciding (De Marchi, Lucertini, \& Tsoukiàs, 2016; Tsoukiàs, Montibeller, Lucertini, \& Belton, 2013).

Therefore, policy makers are faced with different policy alternatives each producing multiple consequences that are difficult to anticipate (Walker, 2000). In this regard, decision analysts can introduce formal methods aimed to assist policy makers in improving their decision aiding processes (De Marchi et al., 2016), allowing the understanding of the complexities, ambiguities and driv- 
ing forces of multi-faceted phenomena (Howlett, McConnell, \& Perl, 2015a).

If supporting the process of policy making needs to be considered within a new framework, then we need to start by reconsidering policy design. A thorough policy design process has a preponderant impact on the quality of the policy alternatives being considered. On top of enhancing the quality of policy alternatives, policy design may enable governments, communities and organizations to address emerging and prevailing problems, as well as opportunities. Few systematic analyses have focused on policy design as the act of generating policy alternatives and even fewer have analysed the pivotal work of the analyst as policy designer (Considine, Alexander, \& Lewis, 2014). Considine et al. (2014) remarked that, despite major advances in the study of public policy, policy design remained uncharted and relatively underdeveloped, notwithstanding the promising works of Alexander (1979, 1982), Dryzek (1983), Linder and Peters (1984), Schneider and Ingram (1988), and Simon (1969) (see Section 2 for a detailed discussion of the literature).

Our contribution in this paper stems from two working hypotheses. The first one is that the intersection among the fields which can contribute to creative policy design (i.e. policy studies, design theory, decision theory and operational research) has not been properly investigated, although the problem is shared among the different fields and some interesting preliminary attempts have been proposed. This hypothesis has been tested and verified in Section 2 of the paper. The second working hypothesis underpinning the development of this research is that it is possible to formalise what generated novelty in the decision aiding process (e.g. using Operational Research tools). This second hypothesis has been tested using two case studies (Sections 3 and 4 of the paper). The two case studies deal with alternatives' generation for territorial policy making and have been analysed using the same analytical lens, shaped by the following four research questions: (i) Why have new alternatives arose during the policy making process? (ii) How have they been generated? (iii) Which consequences did they lead to? and (iv) What generated novelty within the alternatives' design phase of a decision aiding process?

The reminder of the paper is organized as follows: after a state of the art survey (Section 2), the two case studies are presented (Sections 3 and 4). Section 5 concludes the paper by discussing the answers to the research questions presented above.

\section{Designing alternatives for policy making: state of the art}

Designing is the creation of artefacts aimed to change a state of the world that does not suit us (Gero, 1990). This definition echoes the one provided for problem solving by Newell and Simon (Newell \& Simon, 1972), according to whom the solution of a problem consists in the search of the best path connecting the initial state of the problem (i.e. the undesirable state) to the final state (i.e. a more desirable one).

Policy design is one of the major steps in a policy cycle, together with issue identification, defining policy objectives, policy testing, policy finalisation, policy implementation, policy monitoring and evaluation, policy readjustment and innovation (Lasswell, 1956). Within this cycle, policy design can be defined as a specific form of policy formulation based on knowledge gathering about the effects of policy tool use on policy targets and the application of that knowledge to the development and implementation of policies aimed at the attainment of specifically desired public policy outcomes and ambitions (e.g. Bobrow, 2006; Bobrow \& Dryzek, 1987; Capano \& Howlett, 2015). In this context, the artefact is composed by those design features dealing with the implementation of a policy program, while the object of change is the behavior of the implementing agents (Dente \& Busetti, 2015).
From an historical point of view, policy design was recognized quite early as a primary responsibility of the policy sciences (Dror, 1971). Nevertheless, after a promising beginning in the 1970s and 1980s (Alexander, 1982), the field languished in the 1990s and 2000s as work in the policy sciences focused on the impact on policy outcomes of meta-changes in society and the international environment, such as globalization and the enhanced networkization of society (Howlett, 2014). Therefore, policy design did not fare well in the academic agenda (Schneider \& Ingram, 1988) and it was almost equated to the study of policy tools, i.e. focusing almost exclusively on "design as a noun", to the detriment of "design as a process" (Considine et al., 2014). More recent work re-asserting the role of governments both at the international and domestic levels has re-vitalized design studies (e.g. Howlett \& Lejano, 2013; Maskin, 2008).

Being part of the policy cycle, policy design has been explored within the body of literature concerned with policy making. Surprisingly enough, despite the literature on policy making being vast and interdisciplinary, few disciplines have explored specifically policy design. We summarise their contribution in the following paragraphs.

Policy making has been mainly studied in policy analysis (e.g. Moran, Rein, \& Goodin, 2006), with a large body of literature devoted to retrospective (ex post) analysis of policies (e.g. Considine, 2012). Here, much of the design debate was monopolized by literature concerning tools (Salamon, 2002), a largely descriptive body of knowledge which helped identify how policies were designed and - in its most recent developments - looked at the interaction effects of tool mixes (e.g. Howlett, 2005). Equally relevant is the role of prospective (ex ante) analysis, which encompasses the forecasting of consequences if policies were to be implemented and prescriptions about which policies should be implemented (e.g. Dunn, 2012). However, there is little in the literature beyond general prescriptions on how to design policies (Considine, 2012; Tsoukiàs et al., 2013). Within this field, much of the original design literature in the 1960s and 1970s focused attention on "technical" analysis, i.e. assessing the functional capacities of specific policy tools and how they could be applied to achieve policy goals in abstract or imagined unconstrained policy making circumstances (Capano \& Howlett, 2015). The newer design literature keeps this focus but adds to it the need to also assess contextual factors involved in tool choices and use, especially political ones (e.g. Baliga \& Maskin, 2003; Maskin, 2008; Schon, 1992). In particular, this new design orientation focused the attention on the construction over time of policy packages operating in complex multi-policy and multi-level design contexts, thus addressing multiple objectives and exploring the interactive effects which occur when multiple tools are used over time (e.g. Capano \& Howlett, 2015; Doremus, 2003; Howlett et al., 2015b; Howlett \& Ramesh, 2014; Jordan, Benson, Wurzel, \& Zito, 2011).

Equally, economists have been concerned with policy making, focusing much of their research on rational theories of public decision making and formal methods for the ex-ante and ex-post evaluation of public policies (see for instance Dollery \& Worthington, 1996). Cost-Benefit Analysis (see Dasgupta \& Pearce, 1972; Nas, 1996) is widely used and, perhaps, the best known method for evaluating public policies among both practitioners and researchers (e.g. the Cost-Benefit Analysis manual of the European Union $^{1}$ and the World Bank manuals about $\mathrm{CBA}^{2}$ ). However, CostBenefit Analysis is not without contemporary critics (for example, Ackermann, 2010; Adler \& Posner, 2006) and many other ap-

\footnotetext{
${ }^{1}$ http://ec.europa.eu/regional_policy/sources/docgener/guides/cost/guide2008_en. pdf.

2 https://openknowledge.worldbank.org/bitstream/handle/10986/2561/ 624700PUB0Cost00Box0361484B0PUBLIC0.pdf? sequence=1.
} 
proaches have been developed such as, for instance, Real Options Analysis (see Smit \& Trigeorgis, 2004; Trigeorgis, 1990). Economists have developed mechanism design theory (e.g. Hurwicz, 1960; Hurwicz, 1972; Maskin, 1985; Myerson, 1981; Myerson \& Satterthwaite, 1983) to support policy making processes by first identifying the desired outcome or social goal to be achieved, then checking whether or not an appropriate institution (mechanism) could be designed to attain that goal and finally exploring what form that mechanism might take (e.g. Baliga \& Maskin, 2003; Maskin, 2008).

As authors of this paper and decision analysts with expertise in different fields, we are particularly interested in the contribution that Operational Research (OR) and Decision Aiding (Tsoukiàs, 2007) can offer to the field of policy design. OR, unlike economics, does not possess a "world view", i.e. an underlying holistic theory for how the world works (Kaplan, 2016). The natural unit of interest in OR is "the problem", which has to be studied, structured, modeled, understood and, hopefully, improved (Kaplan, 2016).

When it comes to policy making, OR and Decision Analysis have developed, among others, methods which aim at supporting different phases of the policy cycle, such as Problem Structuring Methods (e.g. Checkland, 2000; Pollock, Rothkopf, \& Barnett, 1994; Rosenhead, 2006), System Dynamics (Sterman, 2000; 2001), Data Envelopment Analysis and Performance Measurement (Charnes, Cooper, \& Rhodes, 1979; Cook \& Seiford, 2009; Emrouznejad \& Barnett, 2007) and Public Sector Operational Research (Larson \& Odoni, 1981; Rosenhead, 1981), to name the most relevant ones. However, most emphasis in this stream has been on the evaluation of alternatives, resulting in the development of guidelines for public policy evaluation at different levels (e.g. the Green and Magenta Books of the UK Government, ${ }^{34}$ the Public Policy Assessment Book of the UK Government, ${ }^{5}$ the European Social Fund Manual $^{6}$ ), but with limited consideration to support policy design.

Some interesting attempts to build bridges between OR/Management Science methods and economic analysis for the design of public policies have tested the use of Multiple Criteria Decision Analysis and Multiple Objective Integer Programming/goal programming models and general equilibrium models to provide a range of efficient solutions (e.g. Mavrotas, Ziomas, and Diakouaki (2006) in the field of atmospheric pollution reduction; André, Cardenete, and Romero (2009) for the design of macroeconomic and environmental policies; André and Cardenete (2009) for fiscal policy in Spain; Jayaraman, Colapinto, La Torre, and Malik (2015) for the economic sector in the United Arab Emirates; Kaveri, Hakvoort, and Linares (2017) for renewable energy). However, the focus was typically on combinatorial decision-making problems for the definition of strategies (mixes of measures/modes) based on economic and environmental variables or indicators, which requires a structural model of the economy (e.g. André, Cardenete, \& Romero, 2010). Moreover, the inclusion of individual preferences, as well as the weight of different individuals or groups and their interpersonal comparison of utilities within this type of framework for policy design still needs to be addressed.

Finally, Design theory as well has recently expressed an interest towards the domain of public services, by proposing the operationalisation of general Design theories (e.g. Concept-Knowledge theory, Hatchuel \& Weil, 2009) which could be further explored in policy making contexts.

Let us focus more specifically on the process of designing policies. Being each policy a complex arrangement of on-the-ground

\footnotetext{
3 http://www.hm-treasury.gov.uk/d/green_book_complete.pdf.

4 http://www.hm-treasury.gov.uk/d/magenta_book_combined.pdf.

5 http://www.bis.gov.uk/assets/biscore/better-regulation/docs/i/

11-1111-impact-assessment-guidance.pdf.

${ }^{6}$ http://ec.europa.eu/esf/main.jsp?catId=62.
}

ends and means-related content (Howlett, 2014), they each result in an irreversible allocation of public resources (Tsoukiàs et al., 2013) which needs to be feasible, efficient (i.e. it is not possible to find an alternative that allows improvement in the value of some objectives without harming the value of others (André et al., 2009), and effective with respect to long term results. This definition is resonant with the definition of alternatives as combinations of variables (Williams, 1978), which makes it possible to interpret the concept of policy design in a similar way as the one of alternatives' design.

However, the field of alternatives' design has been almost ignored also in the specialized Decision Science and OR literature. Indeed, most decision problems discussed in the literature consider the set of alternative solutions as "given", although we know that in practice such a set frequently needs to be constructed (Colorni and Tsoukiàs, 2018). There is little in the literature addressing this problem (e.g. Belton \& Stewart, 2002), despite the awareness of it (for example, Goodwin \& Wright, 1998; Keeney, 1996; Keller \& Ho, 1988; Newstead, Thompson, \& Handley, 2002). In particular, Simon (1955) discussed this cognitive activity in his seminal work, but without providing operational and/or formal methods for addressing it. There have also been suggestions for value-focused brainstormings of decision alternatives (Gregory \& Keeney, 2002; Keeney, 1996), an approach which is resonant with dynamic decision problem structuring (Corner, Buchanan, \& Henig, 2001). Finally, insights on how to understand and structure a decision making problem together with its possible strategic directions have been developed within the stream of Soft System Methodologies (e.g. Belton \& Stewart, 2002; Eden, 2004).

A first attempt to identify common points between design theory and decision aiding has been developed by Luè (2015). Indeed, both the design and OR communities have gone through a debate linked to the application of mathematical methods to real world problems. The two communities reacted in different ways, because of the expertise and background of their respective researchers and practitioners. However, they share the same underlying challenge, i.e. designing or aiding decisions in problems which are by definition wicked (or ill-defined, or messy). Moreover, a need for formalized methods to aid the design process seems to have emerged in the design community and at the same time a need for "innovative" tools outside the usual toolbox of the OR practitioner seems to have been highlighted in the OR community (Luè, 2015).

Based on the literature discussed above, the first claim that this paper proposes is thus the following one: the intersection among the fields which can contribute to creative policy design (i.e. policy studies, design theory, decision theory and operations research) has not been properly investigated, although the problem is shared among the different fields. There is thus a need to call for a renewed focus on policy design by means of a convergence of those streams of research, which study how political, policy and strategic decisions are made and implemented, that is how the policy design space is delimited and fulfilled. While these initial sections of the paper proposed a critical analysis of the existing literature, the reminder of the manuscript will focus on two case studies to formalise how new alternatives have been generated within a decision aiding process for policy design.

\section{Case studies: The context}

The two case studies proposed below highlight two processes that lead to the generation of new alternatives. Our aim is to understand and explain what generated novelty within the alternatives' design phase of these two decision aiding processes. 
3.1. Case study 1: Water management in the agricultural system of the Apulia Region (southern Italy)

The first case study deals with water management in the agricultural system of the Apulia Region, and investigates the policy resistance mechanisms hampering the implementation of a water protection policy.

The Apulia Region is highly dependent on agriculture, playing a key role in its economic sector. Due to the limited availability of water resources, the agricultural activities are characterized by the combined use of both surface water (SW) and groundwater (GW), and by the strong impact of the water management framework on Farmers' behaviour (Giordano et al., 2015). The wells are located in Farmers' private properties and for this reason GW is considered a private good. The GW overexploitation depletes water quantity and quality, bringing long term social and environmental problems and requiring more stringent regulation policies (Portoghese et al., 2013). Most of the policies implemented in the Mediterranean basin aim either to improve the efficiency of GW use through innovative irrigation techniques or to restrict the GW use through policies and a tight control of Farmers' activities (Giordano, D'Agostino, Apollonio, Lamaddalena, \& Vurro, 2013).

The Apulia Regional Authority needs to protect GW quality and, at the same time, to keep a high level of productivity of the agricultural sector. To achieve these objectives, the Regional Authority proposed the enforcement of GW restrictive measures (according to the CEE 2000/60). Based on a traditional policy design approach, this policy was defined without considering the potential impacts on the stakeholders (i.e. Farmers and Water Management Authority) and it caused strong conflicts between them. The policy resistance mechanisms mainly occurred due to the economic damages to the agricultural sector, highly dependent on the waterdemanding crops and irrigation practices. Therefore, the restrictive Regional Water Protection Plan (2009) had not been implemented at the time of the study, and the Regional Authority carried on a time/money consuming revision process (Giordano et al., 2015).

This case study represents an emblematic example of the water management complexity, where antagonist Decision Makers, with disparity of objectives and values, need to share the same resource acting according to their problem understanding. A limited understanding of the different problem framings can be a source of conflict, hampering the implementation and/or reducing the effectiveness of environmental policies (Giordano, Brugnach, \& Pluchinotta, 2017).

Considering the two main stakeholders, the Water Management Authority (Consortium of Capitanata) has to deal with the water shortage of the region and with the Farmers water demand. The Consortium manages the SW supply system using two price thresholds for the water volume, i.e. the base water supply volume $\left(0.12 € / \mathrm{m}^{3}\right.$ for $\left.2050 \mathrm{~m}^{3} / \mathrm{ha}\right)$ and the additional water supply volume considerably more expensive $\left(0.36 € / \mathrm{m}^{3}\right.$ for $2050-4000$ $\mathrm{m}^{3} / \mathrm{ha}$ ). According to the Consortium's problem understanding, this pricing strategy would force Farmers to reduce the irrigated areas and to select less water-demanding crops (i.e. less profitable rainfed crops), keeping the water consumption at a sustainable level and ensuring an equal water distribution for the irrigation season (Pluchinotta et al. 2018).

On the other side, Farmers have to share the same resource and to increase their incomes, optimizing the selection of the right mix of crops depending on the quantity of available water (SW and GW) and on the cultivable hectares. The water-demanding crops are more profitable; consequently, the share of irrigated crops (i.e. tomato for processing industry, vineyards, vegetables, olive trees, and orchards) in the area is absolutely dominant compared to the rainfed crops (i.e. durum wheat). However, in dry seasons, Farmers do not have enough SW for their own crops. They receive the in- formation about SW maximum availability very late, and they have two alternatives, such as paying for the most expensive water tariff or using the GW. The Regional Water Protection Plan does not recognize the GW option as an alternative. Nevertheless, Farmers perceive $\mathrm{GW}$ as a cheap and easily accessible resource and the aftereffect is that Farmers tend to use GW. Both stakeholders act as if the decision space was as simple as they presume it to be (i.e. ignoring the role of some of the other actors and/or making assumptions about their decisional processes) (Giordano et al., 2017).

The above indicates that there are discrepancies in the way in which the situation is interpreted by the different stakeholders, leading to a situation of a general dissatisfaction. The generated solutions were considered "optimal" by the policy-maker, while they were not acceptable for the stakeholders. A detailed description of the case study and the analysis of the ambiguity in problem framing can be found in Giordano et al. (2017) and Pluchinotta et al. 2018, while this paper aims to formalise how new alternatives have been discovered during the decision making process under consideration. In Section 4.1, we present the problem formulations from the point of view of the two main stakeholders involved and the consequent introduction of a new variable.

\subsection{Case study 2: Locating a new parking area in a World Heritage} site

The area under investigation in the second case study is the Municipality of Alberobello in southern Italy, which became a UN$\mathrm{ESCO}^{7}$ site in 1996 due to the presence of the "Trulli", a particular form of building construction which derives from prehistoric techniques still functioning in the modern world, thus characterised by a unique value.

Given the increasing flows of people visiting Alberobello's Municipality every year and the severe shortage of parking spaces, the availability of public parking areas has emerged as an issue of serious concern for the local policy makers (Ferretti, 2016).

The decision making context under analysis represents a complex territorial system since being a UNESCO site means that conflicting needs coexist in the same area, i.e. conservation and protection needs as well as new development needs (Ferretti, 2016). The present situation is indeed characterized by heavy traffic problems, roads overcrowded with unregulated parking, high levels of pollution, negative aesthetic impacts and, overall, bad services to tourists and residents. Therefore, the Municipality carried out a technical study and identified five different locations as suitable sites to host a new parking area (Fig. 1).

The general strategy followed by the municipality for the identification of the five suitable sites was based on the reuse as much as possible of former industrial/abandoned areas in order to minimize the consumption of new soil, which is one of the most important aspects of a UNESCO management plan (SiTI (Istituto Superiore sui Sistemi Territoriali per l'Innovazione), 2012). The buffer zone shown in Fig. 1 is the area whose boundaries have been defined in order to protect and maintain the exceptional value of the core area, as well as to limit negative development impacts on it (SiTI Istituto Superiore sui Sistemi Territoriali per l'Innovazione, 2012). All five alternatives represented good options for the Municipality which would have built them all. Given the limited availability of financial resources, the demand was for a priority order for the five proposed alternatives.

A detailed description of the decision support process developed to support the Municipality in the evaluation of the alternative locations for the new parking areas can be found in

\footnotetext{
${ }^{7}$ United Nations Educational, Scientific and Cultural Organisation, http://whc unesco.org/.
} 


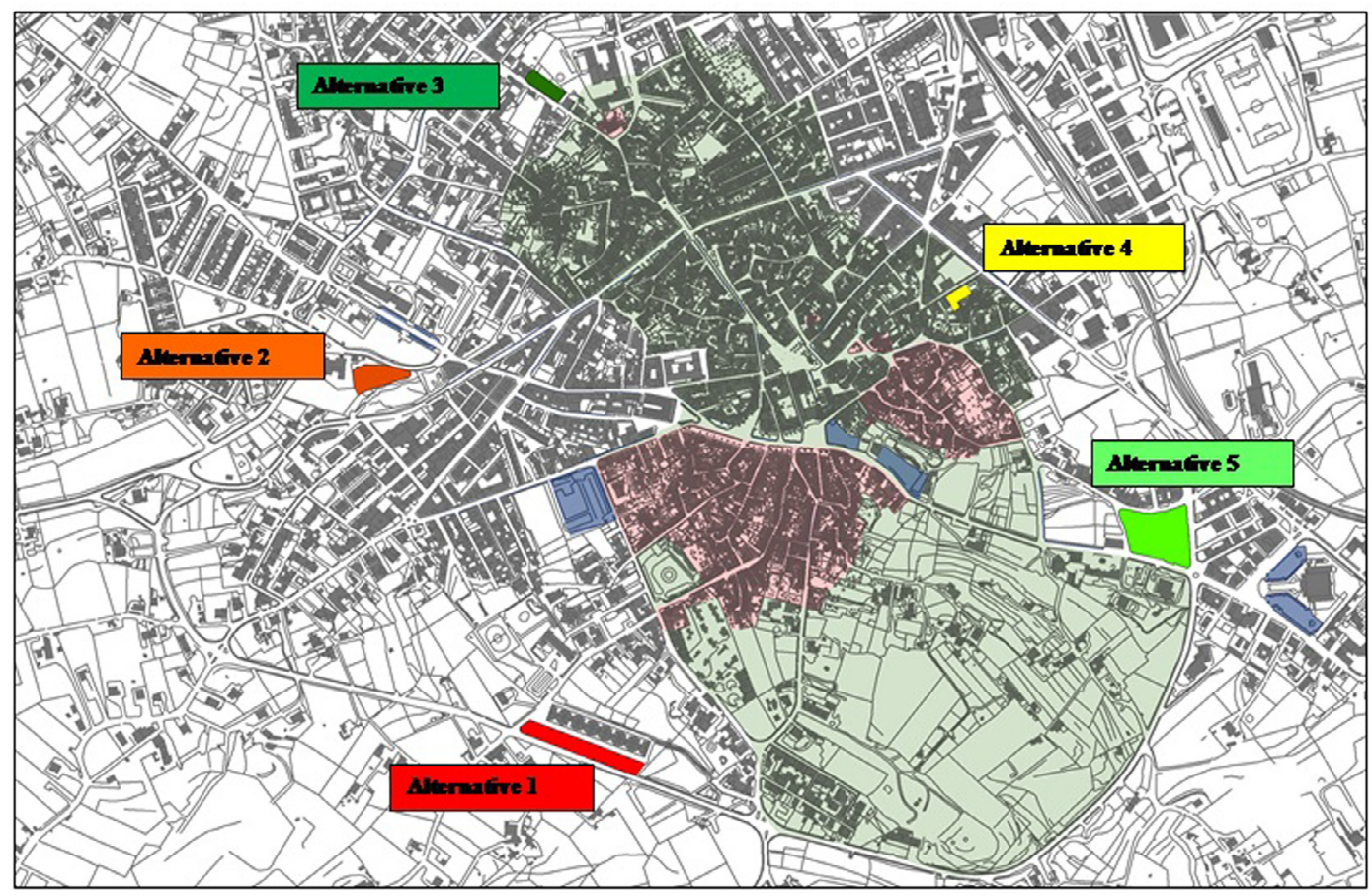

\section{Legend}

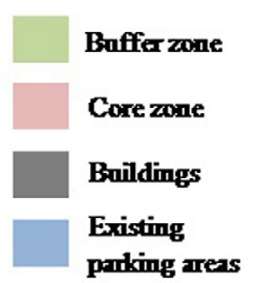

Fig. 1. Suitable alternatives for the location of the new parking area in the municipality of Alberobello (Ferretti, 2016).

Table 1

Key domain elements for the two case studies.

\begin{tabular}{|c|c|c|}
\hline & Case study 1 & Case study 2 \\
\hline Policy goals & $\begin{array}{l}\text { Protect GW quality and quantity keeping high level productivity of } \\
\text { the agricultural sector }\end{array}$ & $\begin{array}{l}\text { (i) Traffic congestion reduction, (ii) minimization of air pollution, } \\
\text { (iii) user experience improvement, for both visitors and residents }\end{array}$ \\
\hline Policy means & $\begin{array}{l}\text { (i) Pricing strategy for water volume reduction, (ii) direct control of } \\
\text { water volume used by farmers }\end{array}$ & $\begin{array}{l}\text { (i) provide parking spaces, (ii) encourage sustainable means of } \\
\text { travel, (iii) taxation }\end{array}$ \\
\hline Time framing & Several years & Several years \\
\hline Stakeholders & $\begin{array}{l}\text { Apulia Region Authority, Water Management Authority, Farmers } \\
\text { (for a detailed presentation of each stakeholder please refer to } \\
\text { Pluchinotta et al. (2018), Giordano et al. (2017)) }\end{array}$ & $\begin{array}{l}\text { Alberobello Municipality, local residents, tourists, cultural } \\
\text { associations, tourist operators, commercial associations, local } \\
\text { practitioners, local entrepreneurs, surrounding municipalities, } \\
\text { disabled people associations, environmental associations, Provincial } \\
\text { government, environmental experts (for the detailed classification } \\
\text { of each stakeholder please refer to Geneletti and Ferretti (2015) }\end{array}$ \\
\hline
\end{tabular}

Ferretti (2016), while a discussion and categorisation of the involved stakeholders can be found in Geneletti and Ferretti (2015).

This paper is intended to shed some light on how to expand the solution space and discover new alternatives for the specific problems under consideration. The formal description of the decision aiding process which exploited the opportunity for a change in one of the variables/constraints of the problem (in this case the increase of the available budget) to generate new alternatives is presented in Section 4.2.

Table 1 summarizes for both case studies the key policy elements at the time the decision aiding processes started.

\section{Case studies: Formal description}

4.1. Case study 1: Generation of a different vision for the agricultural water management system in the Apulia Region

\subsubsection{First formulation}

The current section showcases different problem formulations derived from the work of Giordano et al. (2017). It uses a mathematical programming language which allows to understand rapidly the formal differences of perspective between different problem formulations. Optimization in agriculture is a complex issue char- acterized by interaction of a large number of factors including the assignment of limited resources and information concerning prices (Filippi, Mansini, \& Stevanato, 2017). Our formalizations underline that the dissatisfaction of stakeholders and analyst with the first formulation leads to the identification of a new variable. This process can be considered a starting point to generate new alternatives.

The Regional Authority first formulates a decision problem from its own point of view, let us call it $\Gamma_{1 R}$. The Regional Authority aims at minimising the irrigated practices, promoting a maximization of rainfed crops use.

$$
\begin{aligned}
& \min \sum_{i j} x_{i j}^{d b}+x_{i j}^{d h} \\
& \max \sum_{i j} x_{i j}^{r b}+x_{i j}^{r h}
\end{aligned}
$$

subject to

$\begin{array}{ll}\sum_{i j} x_{i j}^{d b}+x_{i j}^{d h}+x_{i j}^{r b}+x_{i j}^{r h} & \leq F_{t o t} \\ \sum_{i j} w_{j}^{r} x_{i j}^{r b} & \leq W_{\text {min }}\end{array}$ 
$\sum_{i j} p_{j} k_{j}\left(x_{i j}^{d b}+x_{i j}^{d h}+x_{i j}^{r b}+x_{i j}^{r h}\right)$

$-\sum_{i j} c_{b}\left(x_{i j}^{d b}+x_{i j}^{r b}\right)-\sum_{i j} c_{h}\left(x_{i j}^{d h}+x_{i j}^{r h}\right) \quad \geq R$

$\forall i \sum_{j} w_{j}^{d} x_{i j}^{d b}+w_{j}^{r} x_{i j}^{r b}=W_{i}^{b}$

$\forall i \sum_{j} w_{j}^{d}\left(x_{i j}^{d b}+x_{i j}^{d h}\right)+w_{j}^{r}\left(x_{i j}^{r b}+x_{i j}^{r h}\right) \quad=W_{\text {iТОТ }}$

where $x_{i j}^{l t}$ represents the land (hectares) cultivated by Farmer $i$ on crop $j$, while the two superscripts $l$ and $t$ can take two values, respectively: $b, h$ (base and additional) as far as the pricing of the water supply is concerned and $r, d$ (rainfed and water-demanding) as far as the type of crop is concerned. Just to make an example, $x_{11}^{b d}$ represents the land owned by Farmer 1 farmed with crop 1 which is water-demanding $d$ and is irrigated using base priced water $b ; w_{j}^{d}$ is the volume of water necessary (by hectare) for crop $j$ (which is water-demanding), while $w_{j}^{r}$ represents the same information but in case $j$ is a rainfed crop; $p_{j}$ is the revenue ( $\left.€ / h a\right)$ and $k_{j}$ is the yield ( $h a$ ) for each class of crop $j$ (being water-demanding or rainfed). Within this problem formulation, the Consortium considers only two classes of available water supply volume, i.e. the minimum guaranteed to Farmers $W_{\min }$ and the total available $W_{\text {tot }}$; we call the difference between the two as additional or surplus: $W_{h}$. To discourage the use of water in order to reduce the water demand, driving crop diversification according to the Regional Water Protection Plan (see Section 3.1), the Consortium decides to increase significantly the price of the additional water supply volume $c_{h}\left(0.36 € / \mathrm{m}^{3}\right.$ for $\left.2050-4000 \mathrm{~m}^{3} / \mathrm{ha}\right)$, while the price of the base water supply volume $c_{b}\left(0.12 € / \mathrm{m}^{3}\right.$ for $\left.2050 \mathrm{~m}^{3} / \mathrm{ha}\right)$ is still reasonable for the Farmers' budget. $F_{\text {tot }}$ represents the total amount of hectares of the area under analysis, $W_{i}^{b}$ represents the basic water supply allocated to Farmer $i, W_{\text {ітот }}$ the global water supply to Farmer $i$, while $R$ represents a sustainable revenue for the Farmers.

In order $\Gamma_{1 R}$ to hold, the hypothesis is that Farmers reason with the problem formulation $\Gamma_{1 F}$. Farmers know the total quantity of available water in the reservoir $W_{\text {tot }}\left(\mathrm{m}^{3}\right)$ and that the Consortium firstly distributes fairly the base water supply volume $W_{\min }$ to each Farmer. Each Farmer owns a limited agricultural area $F_{i}$, knows the available water either basically priced $W_{i}^{b}$ or highly priced $W_{i}^{h}$ and wants to cultivate different types of crops, aiming to maximize her/his profits. Following this idea we get $\Gamma_{1 F}$ :

$\forall i \max \sum_{j} p_{j} k_{j}\left(x_{i j}^{d b}+x_{i j}^{d h}+x_{i j}^{r b}+x_{i j}^{r h}\right)$

$-\sum_{j} c_{b}\left(x_{i j}^{d b}+x_{i j}^{r b}\right)-\sum_{j} c_{h}\left(x_{i j}^{d h}+x_{i j}^{r h}\right)$

subject to

$\sum_{j} x_{i j}^{d b}+x_{i j}^{d h}+x_{i j}^{r b}+x_{i j}^{r h}$

$\sum_{j} w_{j}^{d} x_{i j}^{d b}+w_{j}^{r} x_{i j}^{r b}$

$$
=W_{i}^{b}
$$

$\sum_{j} w_{j}^{d}\left(x_{i j}^{d b}+x_{i j}^{d h}\right)+w_{j}^{r}\left(x_{i j}^{r b}+x_{i j}^{r h}\right) \quad=W_{i \text { ТО }}$

If $c_{h}>c_{b}$, it is obvious that the best policy consists in minimising the part of land irrigated with "expensive" $\left(c_{h}\right)$ water. If the prices are appropriately calculated, considering the yield of the rainfed and water demanding crops and the revenue they produce, it is possible to obtain a Farmer's policy where cropping rainfed cultures is "convenient". This should produce the expected result consisting in minimising water demanding agriculture. However, this is not what occurs in reality, where Farmers keep increasing the part of land dedicated to water demanding cultures (which typically produce a higher revenue). How can this happen? The reason is simple: most of the Farmers have access to GW (through wells which most of the times are considered as private property). Once the "cheap" $\left(c_{b}\right)$ water has been consumed the Farmers will not go for the expensive one, but start using GW which they pump from their wells. In other terms, we can make the hypothesis that the real decision model each Farmer uses is different from the bilevel model that the Consortium considers.

\subsubsection{Second formulation}

Let us consider now a new problem formulation $\Gamma_{2 F}$ (see Eq. (3)) which should fit better our hypothesis about the Farmers' policy. In this case we first need to consider the availability of GW for each Farmer $\left(W_{i}^{g}\right)$ and then we need to enhance the decision variables: $x_{i j}^{l t}$ will always describe the structure of the variables set, but now the possible options for superscript $l$ will be $b, h, g$ in order to consider land irrigated using GW (priced appropriately: $c_{g}$ ). In other terms, the variables of the type $x_{i j}^{g t}$ stands for land of Farmer $i$, cropping $j$ which can be either rainfed $(r)$ or irrigated $(d)$, but irrigated using GW $(g)$.

$$
\begin{aligned}
& \forall i \max \sum_{j} p_{j} k_{j}\left(x_{i j}^{d b}+x_{i j}^{d h}+x_{i j}^{d g}+x_{i j}^{r b}+x_{i j}^{r h}+x_{i j}^{r g}\right) \\
& -\sum_{j} c_{b}\left(x_{i j}^{d b}+x_{i j}^{r b}\right)-\sum_{j} c_{h}\left(x_{i j}^{d h}+x_{i j}^{r h}\right) \\
& -\sum_{j} c_{g}\left(x_{i j}^{d g}+x_{i j}^{r g}\right)
\end{aligned}
$$

subject to

$$
\begin{aligned}
& \sum_{j} x_{i j}^{d b}+x_{i j}^{d h}+x_{i j}^{d g}+x_{i j}^{r b}+x_{i j}^{r h}+x_{i j}^{r g} \quad \leq F_{i} \\
& \sum_{j} w_{j}^{d} x_{i j}^{d b}+w_{j}^{r} x_{i j}^{r b} \quad=W_{i}^{b} \\
& \sum_{j} w_{j}^{d} x_{i j}^{d g}+w_{j}^{r} x_{i j}^{r g} \quad=W_{i}^{g} \\
& \sum_{i} w_{j}^{d}\left(x_{i j}^{d b}+x_{i j}^{d g}+x_{i j}^{d h}\right)+w_{j}^{r}\left(x_{i j}^{r b}+x_{i j}^{r g}+x_{i j}^{r h}\right) \quad=W_{i T O T}
\end{aligned}
$$

where $c_{g}$ is the price of GW and, according to the actual situation, $c_{h}>c_{g}>c_{b}$. There are two considerations to make here. We firstly did a simplification considering that the price for pumping $\mathrm{GW}$ is the same for all Farmers: this is not far from the reality; however, is not relevant for our reasoning. The second consideration has to do with the perception of this cost (pumping GW): since the wells exist and water they access is considered private, the Farmers do not perceive any real cost besides the operational cost necessary to run the pumps. This perceived cost is far from what the real cost would be if the GW had to be "sold" (as happens for the water provided by the Consortium).

It is interesting to note that the differences between the two problem formulations reveal that the Farmers have a larger and richer solution space, practically ignored by the Water Management Authority and the Regional Authority. These differences stand for discrepancies on how the water management problems is perceived and interpreted by the different stakeholders. The Regional Authority through the Water Protection Plan acted within a partial decision space. The result is a Plan which is de-facto not sustainable for a very simple reason: it is neither applied nor applicable.

Let us make one step further and let us see how a Regional policy could be defined as a result of a problem formulation which should consider the Farmers' real policies. We call this problem 
$\Gamma_{2 R}:$

$\min \sum_{i} w_{i}^{g}$

$\min \sum_{i j} x_{i j}^{d b}+x_{i j}^{d h}+x_{i j}^{d g}$

$\max \sum_{i j} x_{i j}^{r b}+x_{i j}^{r h}+x_{i j}^{r g}$

subject to

$\sum_{i j} x_{i j}^{d b}+x_{i j}^{d h}+x_{i j}^{d g}+x_{i j}^{r b}+x_{i j}^{r h}+x_{i j}^{r g}$

$\sum_{i j} p_{j} k_{j}\left(x_{i j}^{d b}+x_{i j}^{d h}+x_{i j}^{d g}+x_{i j}^{r b}+x_{i j}^{r h}+x_{i j}^{r g}\right)$

$-\sum_{i j} c_{b}\left(x_{i j}^{d b}+x_{i j}^{r b}\right)-\sum_{i j} c_{h}\left(x_{i j}^{d h}+x_{i j}^{r h}\right)$

$-\sum_{i j} c_{g}\left(x_{i j}^{d g}+x_{i j}^{r g}\right)$

$\geq R$

$\forall i \sum_{j} w_{j}^{d} x_{i j}^{d b}+w_{j}^{r} x_{i j}^{r b} \quad=W_{i}^{b}$

$\forall i \sum_{j} w_{j}^{d}\left(x_{i j}^{d b}+x_{i j}^{d h}+x_{i j}^{d g}\right)+w_{j}^{r}\left(x_{i j}^{r b}+x_{i j}^{r h}+x_{i j}^{r g}\right) \quad=W_{i T O T}+w_{i}^{g}$

The reader will note that the introduction of the new variables $w_{i}^{g}$ and $x_{i j}^{l g}$ defines new possible solutions previously inconceivable. It is also clear that if previously the instrument for implementing a policy was the price of the water provided by the Consortium, in order to implement a policy within the new problem formulation it is necessary to define new policy strategies related to the GW price. However, this is presently impossible: there is no precise cartography showing where the wells are located and there is no way to put a price upon the GW. This precise situation may induce the following actions: map the wells and then suggest the establishment of an agency (similar to the existing Consortium) which should manage the GW. After all if the Consortium is legitimated to price the SW why should it not be possible to create a legitimated agent managing the GW? Besides allowing to make operational decisions as far as the level of GW exploitation is concerned, it could introduce more awareness among the Farmers about the risks (and the cost) of overexploiting the aquifers.

4.2. Case study 2: Expanding the solution space for the Alberobello Municipality from single parking areas to combinations of parking slots

\subsubsection{First formulation}

This section proposes an ex-post reconstruction of the process developed in Ferretti (2016), highlighting how the opportunity for a change in one variable/constraint of the problem can support the generation of new alternative solutions.

More specifically we denote $X=\left\{x_{1}, x_{2}, x_{3}, x_{4}, x_{5}\right\}$ the set of the five alternative parking sites under analysis, which are all considered as feasible and desirable ones. However, given the budget constraints, the Decision Maker was only considering the hypothesis of constructing one (possibly the less expensive and possibly the best compromise in terms of parking capacity, environmental impact and landscape impact).

Under such a perspective the problem can be formulated in a simple way: identify the best solution (according to cost, parking capacity and impacts) among the elements of the set $X$ (see Eq. (5)). In other terms, we are looking for the solution to the problem:

$\sup (X \times X)$ where $\succ \subseteq X^{2}$ is an ordering relation upon the set $X$ such that $x_{i} \succ x_{j}$ stands for $x_{i}$ being preferred to $x_{j}$ for one or more criteria considered all together. At this point it does not really matter how the preference is constructed, but the fact that this relation is established upon the set $X$, the objective being to choose one among the possible parking lot solutions.

Consider now the case for which the Decision Maker discovers the possibility of applying for some funding from an international Agency. This type of funding can be used for management projects concerning the area. This new availability of economic resources allows the Decision Maker to take into account other factors which play an important role in managing a UNESCO site, thus shifting from a mono-criterion formulation of the problem to a multiple criteria one. The new dimensions of the problem which were considered as the most important aspects by the Decision Maker were the distance from tourist attractions $d_{j}$ and the aesthetic impact on the landscape $l_{j}$ of each parking location $x_{j}$. The reader interested in the original data considered by the Decision Maker can refer to the study described in Ferretti (2016).

\subsubsection{Second formulation}

Given that the amount of extra funding which might become available for the Municipality will still not allow to build the five parking lots all together, the new formulation of the problem still has a constraint on the increased budget such that a number of maximum $k$ parking lots (out of the five possible locations) can be constructed simultaneously (see Eq. (6)). As a result, we are now trying once again to solve a ranking problem:

$\sup \left(2_{k}^{X} \times 2_{k}^{X}\right)$

but the ordering relation will not apply upon the set $X$, but upon the set $2_{k}^{X}$ which are the subsets of $X$ with cardinality $k$. This second formulation allows the Decision Maker to investigate possible combinations of parking sites (i.e. the Decision Maker is not constrained any more to build only one parking but can build more of them at the same time, provided they still fit within the budget). In this new formulation every alternative becomes a combination of $k$ parking lots, each being described by a vector of attributes (cost, impact on landscape, distance from tourist attractions, etc.). While considering multiple criteria and structuring them according to a Multi Attribute Value Theory framework (Ferretti, 2016), the Decision Maker realised that, if combinations of parking lots become feasible to build, then the direction of preference on each attribute is not independent from the others anymore. For example, distance is not evaluated any more as "the closer, the better" because, with a combination of parking areas, one parking could be more central (to leave the tourist at the beginning of the tourist path), another one could be far from the center (for the tourist buses to wait during the day) and another one could be close to the core UNESCO area again (to pick up the tourists at the end of the visit). The same kind of reasoning applies for the "impact on the landscape" criterion, which can now be negative for the parking in the combination which is far from the core UNESCO area and thus used as a waiting area for the buses which have already left the tourists in the core UNESCO area. The preferences on the distance from the tourist attractions and on the impact on the landscape are thus dependent. This calls for a new formulation of the problem.

\subsubsection{Third formulation}

In the third formulation of the problem, we use preferences nets (CP nets) (see for instance Boutilier et al., 2004), to account for dependent preferences between different alternatives in the decision space.

We consider the parking location problem with $X=$ $\left\{x_{1}, x_{2}, x_{3}, x_{4}, x_{5}\right\}$ set of all potential alternatives, $\mathcal{A}=\left\{\alpha_{1}, \alpha_{2}, \alpha_{3}\right\}$ 


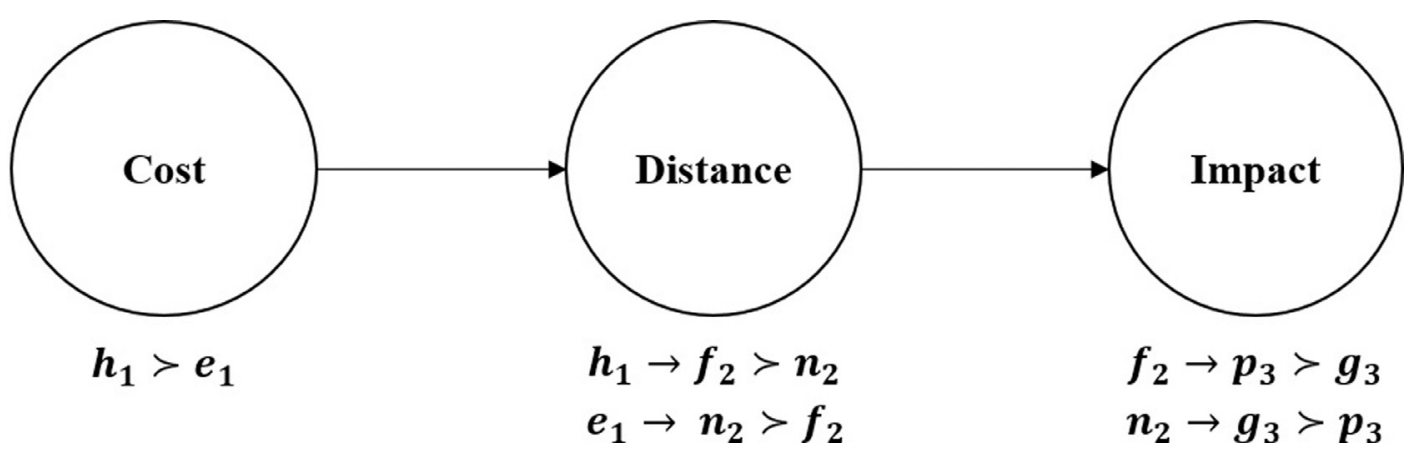

Fig. 2. Conditional preference order on attributes describing the parking location problem.

Table 2

Conditional preference structure of the parking location problem.

\begin{tabular}{ll}
\hline & $h_{1} \succ e_{1}$ \\
\hline$h_{1} \rightarrow$ & $f_{2} \succ n_{2}$ \\
$e_{1} \rightarrow$ & $n_{2} \succ f_{2}$ \\
$f_{2} \rightarrow$ & $p_{3} \succ g_{3}$ \\
$n_{2} \rightarrow$ & $g_{3} \succ p_{3}$ \\
\hline
\end{tabular}

Table 3

Performances of the alternatives with reference to the attributes: cost $\left(\alpha_{1}\right)$, distance $\left(\alpha_{2}\right)$ and impact on the landscape $\left(\alpha_{3}\right)$.

\begin{tabular}{llll}
\hline $\mathcal{A}$ & $\alpha_{1}$ & $\alpha_{2}$ & $\alpha_{3}$ \\
\hline$x_{1}$ & $e_{1}$ & $f_{2}$ & $p_{3}$ \\
$x_{2}$ & $e_{1}$ & $f_{2}$ & $g_{3}$ \\
$x_{3}$ & $h_{1}$ & $n_{2}$ & $g_{3}$ \\
$x_{4}$ & $e_{1}$ & $n_{2}$ & $p_{3}$ \\
$x_{5}$ & $e_{1}$ & $f_{2}$ & $g_{3}$ \\
\hline
\end{tabular}

set of binary attributes, such that $\mathcal{A}_{l}=\left\{h_{1}, e_{1}, n_{2}, f_{2}, p_{3}, g_{3}\right\} . \mathcal{A}_{l}$ represents the set of all possible values that the elements of $\mathcal{A}$ can take. Specifically, the attributes are the cost of each alternative, " $e$ " expensive or " $h$ " cheap, the distance from tourist sites, " $n$ " near or " $f$ " far, and the impact on the landscape, " $p$ " positive or " $g$ " negative.

The conditional preference structure is presented in Table 2 and Fig. 2.

The resulting lattice $\mathcal{L}_{m}$, representing the ordered arrangement of the attributes, is showed in Fig. 3.

Given that the available budget would allow to build not more than three parking lots together, the problem is to choose the best subset of three locations among the five available ones. In this case the solution can be obtained directly from the lattice, this subset being $\left\{x_{1}, x_{3}, x_{4}\right\}$. First we chose a cheap location $\left(x_{3}: h_{1} n_{2} g_{3}\right)$ independent from other attributes. Among the remaining alternatives, which are all expensive, we chose the one nearest $\left(x_{4}: e_{1} n_{2} p_{3}\right)$, and among the remaining ones the one with a positive impact on the landscape $\left(x_{1}: e_{1} f_{2} p_{3}\right)$ (Table 3$)$. Interested readers should note that, despite similarities, this is not a lexicographic order since preferences on lower ranked criteria depend on preferences on higher ranked criteria.

This final formulation of the problem allows the Decision Maker to discover the combination of parking areas that satisfied him most, i.e. a network of parking areas where buses can first take the tourists (alternative 1), then park in areas that are less interesting from the panoramic point of view (alternative 4) and then come later on to pick up the tourists, at the end of the tour and at another location (alternative 3).

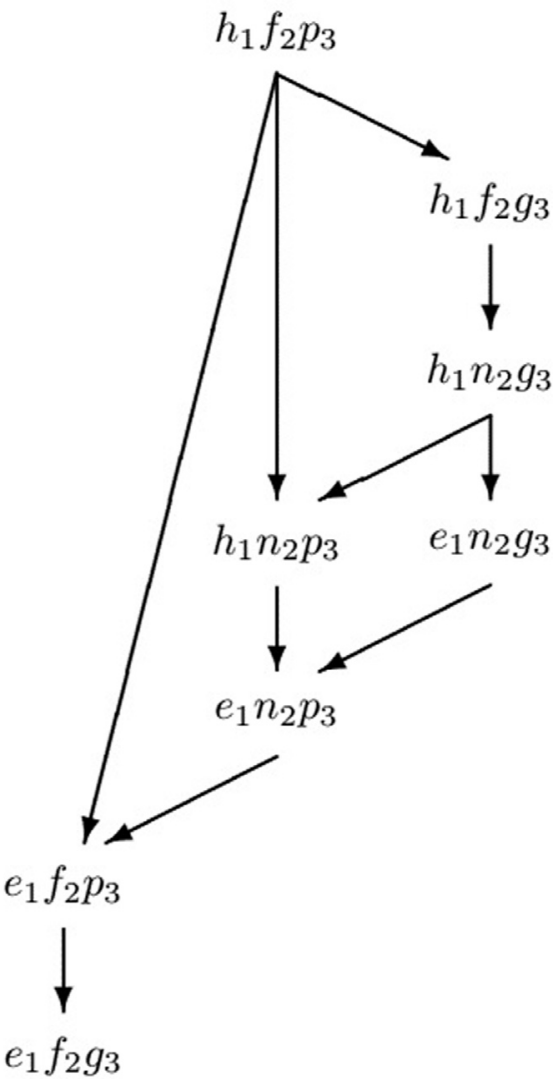

Fig. 3. The resulting attributes' space $\mathcal{L}_{m}$ for the parking location problem.

\section{Discussion and conclusions}

This paper analysed two case studies dealing with territorial policy making aiming to understand and explain what generates novelty within a decision aiding process. In this section, we summarise our answers to the research questions that we formulated in the introduction, i.e. (i) Why have new alternatives arose during the policy making process in the two case studies? (ii) How have they been generated? (iii) Which consequences did they lead to? and (iv) What has generated novelty within the alternatives' design phase of the decision aiding process?.

The first case study deals with two different problem formulations, allowing to investigate the policy resistance mechanisms hampering the implementation of the GW protection policy in the Apulia Region. Concerning our research questions, we could report that: 
(i) A new alternative has been conceived after the unsustainability of the water management system and the general dissatisfaction derived from the first formulation, where one of the stakeholders' decision space was neglected (i.e. the Farmers' ones). A limited understanding of the different problem framings was a source of conflict, reducing the effectiveness of the Regional GW protection policy.

(ii) The differences between the formulations underline that there are discrepancies in the way in which the situation is interpreted by the different stakeholders, leading to the identification of a new variable of the decision space. The new alternative (i.e. available GW resource according to Farmers' perception) has been identified and integrated into the decision model.

(iii) The main consequence of the identification of the new alternative is a better understanding of the observed policy resistance mechanism. The Farmers' resistance behaviour mainly occurred due to the economic damages originated from the GW restrictive use strategy to the agricultural sector, highly dependent on irrigation practices. A complete decision model can be considered a starting point to generate new policy alternatives for water management and GW protection.

(iv) In view of the current situation, the Regional Authority's policy efforts are neutralized by Farmers' behaviors. Farmers continue to use as much GW volume as they can, aiming to maximize their profits per hectare. What generated novelty in this case study is the opportunity to introduce the GW as variable in the decision model in order to redefine the policy alternatives.

In the second case study, we analysed an urban planning process in a World Heritage site dealing with the location of a new parking area. Below the answers to our research questions:

(i) A relaxation on the budget constraint allowed to expand the solution space by conceiving a new alternative (i.e. a combination of parking locations rather than mutually exclusive sites) which was not foreseen at the beginning of the process and which seemed to satisfy better the Decision Maker. This discovery may indeed work as a stimulus to actively seek extra funding opportunities during further negotiation processes in similar as well as in different projects.

(ii) The new "solution" (i.e. the combination of parking lots 1 , 3 and 4 in Figure 1) has been generated through a multi attribute decision making process able to consider preference dependency among the considered attributes.

(iii) As a consequence of the development and discussion of this new alternative, the participants in the process gained a better understanding of the value trade-offs existing between the attributes under consideration, e.g. they realized that, when considering a system of parking lots, they are willing to accept a weaker performance on the "aesthetical impact on the landscape" if the location of the parking is less central. Preferences are indeed constructed (Beinat, 1997) and the learning effect which takes place during the decision making process is one of the most important impacts of Decision Analysis.

(iv) What generated novelty in this case study was the opportunity for a change in one of the variables/constraints, i.e. the possible increase in the available budget thanks to the opportunity to apply for external funding. This highlights that a possible best practice for multi attribute decision making processes, always depending on the specific characteristics of the problem under analysis, might be to compute an overall performance score for each alternative for the benefit-type of attributes and an overall performance score for each alternative for the cost-type of attributes and only after combining these two scores. This would indeed allow to avoid constraining the solution space due to the available budget and stimulate the search for better and more creative alternatives. It is worth highlighting that in this case study the opportunity for a change in one of the variables concerned the possible increase of the available budget, in other policy contexts the change may concern other variables which may not be easily included in the initial negotiation process.

Thanks to the analysis of the above case studies, we have identified two possible reasons for an expansion of the solution space: i) dissatisfaction (of the client, of the analyst or of the relevant stakeholders, especially when we are dealing with public policies) with respect to the solutions currently proposed to the decision making problem; and ii) opportunity for a change in one of the variables/ constraints (e.g. increase in the available budget). These two mechanisms echo two well-known reasons for theory change (Alchourron, Makinson, \& Makinson, 1985), i.e. revision (i.e. an internal modification) and update (i.e. an external modification). In our case the revision corresponded to a change in the expectations of the client/stakeholders and an update corresponded to the discovery that something has changed in the context of the project, e.g. the budget. In our two studies, the consequence of the presence of a dissatisfaction feeling or a new opportunity is a change in a variable of the decision model (in case study 1, the GW consumption which is not considered 0 anymore but can have positive values and, in case study 2 , the budget constraint which has been softened).

It is worth underlining that the alternatives' evaluation represents the subsequent phase of the decision aiding process (e.g. Tsoukiàs, 2007). It is in this phase that the risks of inferior solutions (e.g. less effective, less efficient, less robust against future scenarios) can be addressed (e.g. Belton \& Stewart, 2002).

Lastly, we acknowledge that generalising our findings warrants caution for several reasons. First, this paper discusses findings from only two case studies. It is the hope of the authors that the lessons learned through these two case studies can stimulate further researches on the generation of alternatives in policy design. Secondly, what we proposed is an ex post analysis of two case studies, rather than a real time account of the policy design process. Thus, future research could explore the replicability of our answers across other policy making interventions. Thirdly, we acknowledge that not all problems can be formalised in mathematical terms. The two case studies we proposed were indeed suitable to be mathematically formalised but were dealing with a limited number of variables and constraints. Increasing the number of variables/constraints would certainly represent a further complexity in solving the problem. Undoubtedly, new alternatives can be generated using other OR techniques such as inverse optimisation (e.g. Ahuja \& Orlin, 2001; Roland, De Smet, \& Rui Figueira, 2013) which allow dominated solutions (generally neglected), to become nondominated with a minimal adjustment of the problem parameters (e.g. objective functions coefficients).

In conclusion, this paper has showed that novelty in the alternatives' design phase of a decision aiding process can come through a change in a variable/constraint which then allows to expand the solution space. Although increasing the number of variables/constraints certainly represents a supplementary difficulty of solving the problem, what we learned from this study is that the possible expansion of the solution space is obtained through the evolution of problem formulations, due to revision and/or update, such that both the client and the analyst enrich their perspectives, improve their problem insight and establish mutual satisfaction. Design and decision theory could be a promising tool to support in a formal way this expansion of the solution space within a policy making process. Indeed, the use of multi-disciplinary approaches in both case studies (i.e. socio-environmental participatory modelling, system dynamics and problem structuring methods in case study 1 (Pluchinotta et al., 2018; Giordano et al., 2017); cognitive mapping with participatory planning and multi criteria decision analysis in case study 2 (Ferretti, 2016; Geneletti \& Ferretti, 2015)) 
highlights the need for the convergence of multiple fields to improve policy making processes.

\section{References}

Ackermann, F. (2010). Priceless: On knowing the price of everything and the value of nothing. The New Press. doi:10.1136/bmj.330.7499.1091.

Adler, M., \& Posner, E. (2006). New foundations of cost benefit analysis. Harvard University Press.

Ahuja, R. K., \& Orlin, J. B. (2001). Inverse optimization. Operations Research, 49(5), 771-783, doi:10.1287/opre.49.5.771.10607.

Alchourron, C. E., Makinson, P. G., \& Makinson, D. (1985). On the logic of theory change: partial meet contraction and revision functions. The Journal of Symbolic Logic, 50(2), 510-530.

Alexander, E. R. (1979). The design of alternatives in organizational contexts: A pilot study. Administrative Science Quarterly, 24(September), 382-404. doi:10.2307/ 2989919.

Alexander, E. R. (1982). Design in the decision-making process. Policy Sciences, 14, 279-292.

Anderson, J. (1975). Public policy making. New York: Praeger Publishing.

André, F. J., \& Cardenete, M. A. (2009). Defining efficient policies in a general equilibrium model: a multi-objective approach. Socio-Economic Planning Sciences, 43(3), 192-200. doi:10.1016/j.seps.2008.11.001.

André, F. J., Cardenete, M. A., \& Romero, C. (2009). A goal programming approach for a joint design of macroeconomic and environmental policies: A methodological proposal and an application to the spanish economy. Environmental Management, 43(5), 888-898. doi:10.1007/s00267-009-9276-x.

André, F. J., Cardenete, M. A., \& Romero, C. (2010). Designing public policies: An approach based on multi-criteria analysis and computable general equilibrium modeling. Berlin Heidelberg: Springer-Verlag. doi:10.1007/978-3-642-12183-8.

Baliga, S., \& Maskin, E. (2003). Mechanism design for the environment. In Maler K., Arrow K., Intriligator M., \& Vincent J. (Eds.), Handbook of environmental economics: 1 (pp. 305-324). Berlin: Elsevier Science. series eds.

Beinat, E. (1997). Value functions for environmental management. Dordrecht: Kluwer Academic Publishers.

Belton, V., \& Stewart, T. (2002). Muliple criteria decision analysis: An integrated approach. Dordrecht: Kluwer Academic.

Bobrow, D. (2006). Policy design: Ubiquitous, necessary and difficult. In Guy Peters B., \& Pierre Jon (Eds.), Handbook of public policy (pp. 75-96). SAGE.

Bobrow, D., \& Dryzek, J. S. (1987). Policy analysis by design. Pittsburgh: University of Pittsburgh Press.

Boutilier, C., Brafman, R. I., Domshlak, C., Hoos, H. H., \& Poole, D. (2004). CP-nets: A Tool for Representing and Reasoning withConditional Ceteris Paribus Preference Statements. Journal Of Artificial Intelligence Research, 21, 135-191.

Capano, G., \& Howlett, M. (2015). Design and non-design in policy-making: When and how policy design matters. In Proceedings of the ECPR workshop on "design and non-design in policy making: when and how policy design matters". Policy formulation and the changing dynamics of public policy (pp. 1-19). Warsaw.

Charnes, E., Cooper, W., \& Rhodes, E. (1979). Measuring the efficiency of decision making units. European Journal of Operational Research, 3, 429-444.

Checkland, P. (2000). Soft systems methodology: A thirty year retrospective.. Systems Research and Behavioral Science, 17, S11-S58.

Colorni, A., \& Tsoukiàs, A. (2018). What is a Decision Problem? Designing Alternatives. In N. Matsatsinis, \& E. Grigoroudis (Eds.), Preference Disaggregation in Multiple Criteria Decision Analysis (pp. 1-15). Switzerland: Springer International Publishing. doi:10.1007/978-3-319-90599-0_1.

Considine, M. (2012). Thinking outside the box? Applying design theory to public policy. Politics and Policy, 40(4), 704-724.

Considine, M., Alexander, D., \& Lewis, J. M. (2014). Policy design as craft: Teasing out policy design expertise using a semi-experimental approach. Policy Sciences, 47(3), 209-225. doi:10.1007/s11077-013-9191-0.

Cook, W. D., \& Seiford, L. M. (2009). Data envelopment analysis - Thirty years on. European Journal of Operational Research, 192, 1-17.

Corner, J., Buchanan, J., \& Henig, M. (2001). Dynamic decision problem structuring. Journal of multicriteria decision analysis, 10(3), 129-141.

Dasgupta, P., \& Pearce, D. (1972). Cost-benefit analysis: Theory and practice. Basingstoke: Macmillan.

De Marchi, G., Lucertini, G., \& Tsoukiàs, A. (2016). From evidence-based policy making to policy analytics. Annals of Operations Research, 236(1), 15-38. doi:10.1007/ s10479-014-1578-6.

Dente, B., \& Busetti, S. (2015). Mechanism-based policy design: expanding designers' toolkit. In Proceedings of the ECPR workshop on "design and non-design in policy making: when and how policy design matters". Policy formulation and the changing dynamics of public policy. Warsaw.

Dollery, B. E., \& Worthington, A. C. (1996). The evaluation of public policy: Normative economic theories of government failure. Journal of Interdisciplinary Economics, 7(1), 27-39.

Doremus, H. (2003). A policy portfolio approach to biodiversity protection on private lands. Environmental Science and Policy, 6(3), 217-232. doi:10.1016/ S1462-9011(03)00036-4.

Dror, Y. (1971). Design for policy sciences. Atlanta: American Elsevier Publishing Company.

Dryzek, J. S. (1983). Don't toss coins in garbage cans: A Prologue to policy design. Journal of Public Policy, 3(4), 345-367. doi:10.2307/3998421.

Dunn, W. (1981). Public policy analysis. An introduction. New Jersey: Prentice Hall.
Dunn, W. (2012). Public policy analysis. Pearson Education.

Dye, T. (1972). Understanding public policy. New Jersey: Prentice Hall.

Eden, C. (2004). Analyzing cognitive maps to help structure issues or problems. European Journal of Operational Research, 159(3), 673-686. doi:10.1016/ S0377-2217(03)00431-4

Emrouznejad, A., \& Barnett, R. (2007). Evaluation of research in efficiency and productivity: A survey and analysis of the first 30 years of scholarly literature in DEA. Socio-Economic Planning Sciences, 42, 151-157.

Ferretti, V. (2016). From stakeholders analysis to cognitive mapping and multiattribute value theory: An integrated approach for policy support. European Journal of Operational Research, 253(2), 524-541. doi:10.1016/j.ejor.2016.02.054.

Filippi, C., Mansini, R., \& Stevanato, E. (2017). Mixed Integer Linear Programming models for optimal crop selection. Computers \& Operations Research, 81, 26-39. doi:10.1016/j.cor.2016.12.004.

Geneletti, D., \& Ferretti, V. (2015). Multicriteria analysis for sustainability assessment: Concepts and case studies. In A. Morrison-Saunders, J. Pope, \& A. Bond (Eds.), Handbook of sustainability assessment (pp. 235-264).

Gero, J. (1990). Design prototypes: A knowledge representation schema for design. AI Magazine, 11(4), 26-36.

Giordano, R., Brugnach, M., \& Pluchinotta, I. (2017). Ambiguity in problem framing as a barrier to collective actions: Some hints from groundwater protection policy in the Apulia region. Group Decision and Negotiation, 26(5), 911-932. doi:10.1007/s10726-016-9519-1.

Giordano, R., D’Agostino, D., Apollonio, C., Lamaddalena, N., \& Vurro, M. (2013). Bayesian belief network to support conflict analysis for groundwater protection: The case of the Apulia region. Journal of Environmental Management, 115, 136 146. doi:10.1016/j.jenvman.2012.11.011.

Giordano, R., D’Agostino, D., Apollonio, C., Scardigno, A., Pagano, A., Portoghese, I. et al. (2015). Evaluating acceptability of groundwater protection measures under different agricultural policies. Agricultural Water Management, 147, 54-66. doi:10.1016/j.agwat.2014.07.023.

Goodwin, P., \& Wright, G. (1998). Decision analysis for management judgment. New York: John Wiley \& Sons.

Gregory, R. S., \& Keeney, R. L. (2002). Making smarter environmental management decisions. Journal of the American Water Resources Association, 38(6), 1601-1612. doi:10.1111/j.1752-1688.2002.tb04367.x.

Hatchuel, A., \& Weil, B. (2009). C-K design theory: An advanced formulation. Research in Engineering Design, 19(4), 181-192.

Howlett, M. (2005). What is a policy instrument? Tools, mixes, and implementation styles. In M. Pearl Eliadis, P. Hill, \& M. Howlett (Eds.), Designing government. from instruments to governance (pp. 31-50). Montreal: McGill-Queen's University Press.

Howlett, M. (2014). From the 'old' to the 'new' policy design: Design thinking beyond markets and collaborative governance. Policy Sciences, 47(3), 187-207. doi:10.1007/s11077-014-9199-0.

Howlett, M., \& Lejano, R. (2013). Tales from the crypt: The rise and fall (and re-birth?) of policy design studies.. Administration E' Society, 45(3), 356-380.

Howlett, M., McConnell, A., \& Perl, A. (2015a). Weaving the fabric of public policies: Comparing and integrating contemporary frameworks for the study of policy processes. Journal of Comparative Policy Analysis: Research and Practice, 18(3), 273-289. doi:10.1080/13876988.2015.1082261.

Howlett, M., Mukherjee, I., \& Woo, J. J. (2015b). From tools to toolkits in policy design studies: The new design orientation towards policy formulation research. Policy and politics, 43(2), 291-311.

Howlett, M., \& Ramesh, M. (2014). The two orders of governance failure: Design mismatches and policy capacity issues in modern governance. Policy and Society, 33(4), 317-327. doi:10.1016/j.polsoc.2014.10.002.

Howlett, M., \& Rayner, J. (2013). Patching vs. packaging in policy formulation: Assessing policy portfolio design. Politics and Governance, 1(2), 170-182. doi:10. 12924/pag2013.01020170.

Hurwicz, L. (1960). Optimality and informational efficiency in resource allocation processes. In A. Kenneth, S. Karlin, \& P. Suppes (Eds.), Mathematical methods in social sciences (pp. 27-46). Stanford: Stanford University Press.

Hurwicz, L. (1972). On informationally decentralized systems. In McGuire C., \& Radner R. (Eds.), Decision and organization (pp. 297-336). Amsterdam: North-Holland.

Jayaraman, R., Colapinto, C., La Torre, D., \& Malik, T. (2015). Multi-criteria model for sustainable development using goal programming applied to the United Arab Emirates. Energy Policy, 87, 447-454. doi:10.1016/j.enpol.2015.09.027.

Jenkins, W. (1978). Policy analysis: A political and organizational perspective. Oxford: Martin Robertson.

Jordan, A., Benson, D., Wurzel, R., \& Zito, A. (2011). Policy instruments in practice. In J. Dryzek, R. Norgaard, \& D. Schlosberg (Eds.), Oxford handbook of climate change and society (pp. 536-549). Oxford: Oxford University Press.

Kaplan, E. (2016). Celebrating the operations research mindset. INFORMS memberin-chief memo. https://www.informs.org/Blogs/E-News-Blog/Member-in-ChiefMemo.

Kaveri, K. I., Hakvoort, R., \& Linares, P. (2017). Towards a comprehensive policy for electricity from renewable energy: An approach for policy design. Energy Policy, 106(August 2016), 169-182. doi:10.1016/j.enpol.2017.03.051.

Keeney, R. L. (1996). Value-focused thinking: A path to creative decision- making. Harvard University Press.

Keller, L. R., \& Ho, J. L. (1988). Decision problem structuring: generating options. IEEE Transactions on Systems, Man and Cybernetics, 18(5), 715-728. doi:10.1109/ 21.21599 . 
Larson, R., \& Odoni, A. (1981). Urban operations research. New Jersey: Prentice-Hall.

Lasswell, H. (1956). The decision process: Seven categories of functional analysis.. College of Business and Public Administration, University of Maryland, Bureau of Governmental Research.

Linder, S. H., \& Peters, B. G. (1984). From social theory to policy design. Journal of Public Policy, 4(3), 237-259. doi:10.1017/S0143814X0000221X.

Luè, A. (2015). Design and decision aiding for mobility services and systems. Politecnico of Milano. Ph.D. Thesis.

Maskin, E. (1985). The theory of implementation in Nash Equilibrium: A survey. In L. Hurwicz, D. Schmeidler, \& H. Sonnenschein (Eds.), Social goals and social organization. Cambridge: Cambridge University Press.

Maskin, E. (2008). How to implement social goals mechanism design. American Economic Review, 98(3), 567-576. doi:10.1257/aer.98.3.567.

Mavrotas, G., Ziomas, I. C., \& Diakouaki, D. (2006). A Combined MOIP-MCDA approach to building and screening atmospheric pollution control strategies in urban regions. Environmental Management, 38(1), 149-160. doi:10.1007/ s00267-005-0111-8.

May, P. J. (1981). Hints for crafting alternative policies. Policy Analysis, 7(2), 227-244.

Moran, M., Rein, M., \& Goodin, G. (2006). The Oxford handbook of public policy. Oxford: Oxford University Press.

Myerson, R. (1981). Optimal auction design. Mathematics of Operations Research, 6, 58-73.

Myerson, R., \& Satterthwaite, M. A. (1983). Efficient mechanisms for bilateral trading. Journal of Economic Theory, 29, 256-281.

Nas, T. (1996). Cost-benefit analysis: Theory and application. Sage Publications.

Newell, A., \& Simon, H. A. (1972). Human problem solving. Prentice Hall: Englewood Cliffs.

Newstead, S. E., Thompson, V., \& Handley, S. J. (2002). Generating alternatives: A key component in human reasoning? Memory E cognition, 30(1), 129-137. doi:10. 3758/BF03195272.

Pluchinotta, I., Pagano, A., Giordano, R., \& Tsoukiàs, A. (2018). A system dynamics model for supporting decision-makers in irrigation water management. Journal of Environmental Management, 223. doi:10.1016/j.jenvman.2018.06.083.

Pollock, S., Rothkopf, M., \& Barnett, A. (1994). Operational research and the public sector. North Holland, Amsterdam.

Portoghese, I., D'Agostino, D., Giordano, R., Scardigno, A., Apollonio, C., \& Vurro, M. (2013). An integrated modelling tool to evaluate the acceptability of irrigation constraint measures for groundwater protection. Environmental Modelling $\mathcal{E}$ Software, 46, 90-103.
Roland, J., De Smet, Y., \& Rui Figueira, J. (2013). Inverse multi-objective combinatorial optimization. Discrete Applied Mathematics, 161(16-17), 2764-2771. doi:10. 1016/j.dam.2013.04.024.

Rosenhead, J. (1981). Operational research in urban planning. Omega, 9(4), 345-364

Rosenhead, J. (2006). Past, present and future of problem structuring methods. Journal of the Operational Research Society, 57(7), 759-765. doi:10.1057/palgrave.jors. 2602206.

Salamon, L. (2002). The new governance and the tools of public action: An introduction. New York: Oxford University Press.

Schneider, A., \& Ingram, H. (1988). Systematically pinching ideas: A comparative approach to policy design. Journal of Public Policy, 8(01), 61. doi:10.1017/ S0143814X00006851.

Schon, D. (1992). Designing as reflective conversation with the materials of a design situation. Knowledge-Based Systems, 5(1), 3-14.

Simon, H. A. (1955). A behavioral model of rational choice. The Quarterly Journal of Economics, 69(1), 99-118. doi:10.2307/1884852.

Simon, H. A. (1969). The sciences of the artificial. Cambridge, MA: MIT Press.

SiTI, (2012). The management plan for the UNESCO world heritage site "Trulli di Alberobello", Technical Report, Istituto Superiore sui Sistemi Territoriali per l'Innovazione.

Smit, H., \& Trigeorgis, L. (2004). Strategic investment: Real options and games. Princeton University Press.

Sterman, J. D. (2000). Business dynamics : systems thinking and modeling for a complex world. Boston: Irwin/McGraw-Hill $982 \mathrm{p}$.

Sterman, J. D. (2001). System dynamics modeling: Tools for learning in a complex world. California Management Rezview, 43(4), 8-25.

Trigeorgis, L. (1990). A real options application in natural resource investments. Advances in Futures and Options Research, 4, 153-164.

Tsoukiàs, A. (2007). On the concept of decision aiding process: An operational perspective. Annals of Operations Research, 154(1), 3-27. doi:10.1007/ s10479-007-0187-z.

Tsoukiàs, A., Montibeller, G., Lucertini, G., \& Belton, V. (2013). Policy analytics: an agenda for research and practice. EURO Journal on Decision Processes, 1(1-2), 115-134. https://doi.org/10.1007/s40070-013-0008-3.

Walker, W. E. (2000). Policy analysis: a systematic approach to supporting policymaking in the public sector. Journal of Multi-Criteria Decision Analysis, 9, 11-27.

Williams, H. P. (1978). Model building in mathematical programming. Chichester, England: John Wiley \& Sons Ltd. 